\title{
INFLUÊNCIA DAS RELAÇÕES DE GÊNERO NAS TÁTICAS DE MARKETING DA MARCA YOUCOM
}

\section{INFLUENCE OF GENDER RELATIONSHIPS ON THE MARKETING TACTICS OF YOUCOM BRAND}

\section{Gabriela Machado Schneider}

Bacharel em Administração de Empresas pela Faculdade IENH. Faculdade IENH, Brasil

E-mail: schneiderm.gabriela@gmail.com

Luciane Pereira Viana

Doutora em Diversidade Cultural e Inclusão Social pela Universidade Feevale. Professora na Faculdade IENH, Brasil. http://orcid.org/0000-0002-9577-728X

E-mail: viana.luciane.lu@gmail.com

Recebido: 20/05/2021 - Aceito: 20/05/2021

\section{Resumo}

O objetivo desse artigo é analisar a influência das relações de gênero nas táticas de marketing da marca Youcom. A Youcom é uma rede de lojas do grupo Lojas Renner que atua no segmento de vestuário. Em seus pontos de venda, a marca não faz a distinção/ segmentação de roupas femininas ou masculinas. Como metodologia realizou-se uma pesquisa descritiva, qualitativa, com uma análise na página do Facebook e do site da marca durante seis meses. A partir da análise dos dados evidenciou-se que a marca possui um forte posicionamento sobre as relações de gênero e seus consumidores percebem esse posicionamento. Observa-se que os assuntos referentes às relações de gênero têm conquistado maior espaço na sociedade devido aos movimentos em busca de igualdade e liberdade de expressão. E, as marcas precisam posicionarse de forma adequada diante de consumidores mais empoderados e atentos, pois estes buscam marcas e produtos ou serviços com os quais se identificam.

Palavras-chave: Táticas de Marketing; Relações de Gênero; Marca Youcom; Branding.

\section{Abstract}

The purpose of this article is to analyze the influence of gender relations on the marketing tactics of Youcom brand. Youcom is a chain of stores of Lojas Renner group that operates in the clothing 
segment. In its selling points, the brand does not distinguish / segment women's or men's clothing. As methodology, a descriptive, qualitative research was carried out, with an analysis was performed on the Facebook page and the brand's website for six months. From the data analysis it became clear that the brand has a strong position on gender relations and its consumers perceive this position. It is observed that issues related to gender relations have gained greater space in society due to movements in search of equality and freedom of expression. And, brands need to position themselves appropriately in front of more empowered and alert consumers, as they seek brands and products or services with which they identify.

Keywords: Marketing Tactics; Gender Relations; Youcom Brand; Branding.

\section{Introdução}

Com o avanço da tecnologia e as alterações na economia, as mudanças estão cada vez mais presentes na vida cotidiana, ocorrendo de modo mais rápido e dinâmico. Os consumidores estão mais conectados e atentos ao que as empresas dizem e efetivamente fazem. Em decorrência dessas mudanças e avanços, as relações de poder entre as empresas e os consumidores estão cada vez mais próximas e sensíveis, passando de relações verticais para relações mais horizontais.

Com tantas mudanças e possibilidades surgindo, acredita-se ser de grande importância refletir sobre as relações de gênero no marketing. Os assuntos referentes às relações de gênero têm conquistado maior espaço na sociedade devido aos movimentos em busca de igualdade e liberdade de expressão. Nesse sentido, o marketing precisa entender e posicionar-se de forma adequada diante de consumidores mais empoderados e atentos, pois estes geralmente buscam marcas e produtos ou serviços com os quais se identificam.

Com base nesse cenário de mudanças, de novas possibilidades, de discussões sobre relações de gênero e empoderamento dos consumidores, a questão de pesquisa identificada é: qual a influência das relações de gênero sobre as táticas de marketing da marca Youcom? E tem como objetivo analisar a influência das relações de gênero nas táticas de marketing da marca Youcom.

A Youcom, objeto de estudo desta pesquisa, é uma rede de lojas do grupo 
Lojas Renner que atua no segmento de vestuário. Em seus pontos de venda, a marca não faz a distinção de roupas femininas ou masculinas, pois as roupas da loja não se encontram segmentadas. Segundo o site do grupo Renner SA (2020) a Youcom foi criada em 2013 com o objetivo de atender exclusivamente o público jovem "antenado" ao mundo da moda. A Youcom possui noventa lojas distribuídas em São Paulo, Rio Grande do Sul, Santa Catarina, Paraná, Distrito Federal, Minas Gerais, Goiás e Salvador, além do site oficial com o e-commerce e realiza entregas para todo o Brasil.

Este artigo é composto por cinco seções. A primeira uma introdução que apresenta a jutificativa, a questão de pesquisa e o objetivo da pesquisa. A segunda seção corresponde ao referencial teórico abordando as temáticas de marketing e suas táticas, gênero e o empoderamento dos consumidores. A terceira apresenta a metodologia utilizada na pesquisa. A quarta contempla os resultados obtidos e análises, e, por fim, a quinta seção apresenta as considerações finais da pesquisa.

\section{Revisão da Literatura}

De acordo com Kotler e Armstrong (2015, p. 3), “[...] marketing é a gestão de relacionamentos lucrativos com os clientes". Na perspectiva de Las Casas (2008), o marketing possui a função principal de satisfazer o consumidor antes, durante e depois da venda, entre indivíduo e organização. O autor também destaca que todos os setores da empresa devem estar engajados nesse objetivo, não deixando a responsabilidade da satisfação dos clientes somente direcionada ao setor de marketing.

Segundo Camarotto (2009) alguns fatores estão influenciando cada vez mais as estratégias de marketing, são eles: maior poder de compra dos consumidores, novas tecnologias, maior oferta no número de produtos ou serviços e a percepção de valor vista pelos clientes. Desta forma, acredita-se que para os autores é fundamental a criação de táticas efetivas com foco em encantar os clientes e o mercado. 


\subsection{Táticas e o composto de marketing}

Segundo Kotler e Armstrong (2015, p. 42) "[...] o mix de marketing é o conjunto de ferramentas de marketing táticas e controláveis que a empresa combina para produzir a resposta que deseja no mercado-alvo. Consiste em tudo que a empresa pode fazer para influenciar a demanda de seu produto". As ferramentas do mix de marketing classificam-se em quatro Ps: produto, preço, praça e promoção:

a) Produto: De acordo com Las Casas (2008), o produto é o objeto principal da comercialização, e cabe aos profissionais de marketing enfatizar os benefícios que os produtos podem trazer aos consumidores. Conforme Kotler e Keller (2013), o produto precisa apresentar a possibilidade de devolução, possuir qualidade, tamanhos e medidas, dados técnicos, características, nome e identificação da marca. Para Kotler e Armstrong (2015), o produto consiste na união de bens e serviços que a empresa disponibiliza para o mercado-alvo.

b) Preço: De acordo com Kotler e Armstrong (2015) o preço é a quantia em dinheiro cobrada por um produto ou serviço, sendo um dos fatores que historicamente afeta a escolha realizada pelo consumidor entre um produto e outro. Las Casas (2008) complementa que, ao comprar um produto ou serviço, os consumidores, além de verificarem o preço, realizam uma crítica em relação ao custo $X$ benefício que o produto ou serviço podem trazer. Conforme os autores, 0 preço é um dos elementos mais flexíveis do mix de marketing, e pode ser ajustado de acordo com o planejamento tático da empresa.

c) Praça: Para Kotler e Armstrong (2015), a praça consiste em ações da empresa que buscam disponibilizar o produto para os consumidores. A praça corresponde às áreas de logística, transporte, estoque, variedade e canais de distribuição. Os autores afirmam que os canais de distribuição afetam de forma direta todos os outros componentes do composto de marketing. Churchill e Peter (2012) corroboram tal afirmação, comentando que os tipos de canais em que o produto é disponibilizado instigam os consumidores sobre a percepção do mesmo. Nesse sentido, cabe ao profissional de marketing tornar o produto disponível e influenciar a compra do consumidor. 
d) Promoção: Conforme Kotler e Keller (2013), a comunicação de marketing é o modo pelo qual as empresas lembram, informam e instigam os consumidores sobre os produtos que vendem. Complementam Kotler e Armstrong (2015) que as empresas devem utilizar a promoção para comunicar os consumidores de maneira clara sobre quais são os valores que elas geram e criar relacionamentos com eles. Parente e Barki (2014) destacam as ferramentas utilizadas pelo marketing para realizar a promoção das empresas:

- Propaganda: é a comunicação paga, impessoal e indireta transmitida por meio de uma mídia. Exemplos: jornais, revistas, televisão, entre outros.

- Promoção de vendas: é uma ferramenta de comunicação direta ou indireta, impessoal, e que oferece um valor para o consumidor. Exemplos: programas de fidelização, prêmios, demonstrações de produtos, entre outros.

- Relações públicas: é a comunicação impessoal e indireta veiculada com a mídia de informações sobre um produto ou uma marca.

- Marketing direto: é a comunicação direta que tem o objetivo de gerar uma resposta com os consumidores. Exemplos: venda direta, telemarketing, gerenciamento de banco de dados, entre outros.

- Marketing interativo: é a comunicação digital utilizando-se da tecnologia e da internet, possibilitando disponibilizar conteúdo em tempo real.

Para Kotler e Keller (2013) os quatro Ps do marketing tradicional já não são suficientes para reproduzir as novas realidades do marketing de uma empresa. Sendo assim, os autores apresentam mais quatro Ps: Pessoas, Processos, Programas e Performace.

e) Pessoas: De acordo com Cobra e Urdan (2017) são as pessoas que interagem com os consumidores, sendo essas as responsáveis por transmitir a imagem da empresa. Dessa forma, pessoas motivadas podem criar uma boa experiência para os consumidores. Entretanto, um colaborador desmotivado pode não oferecer um bom atendimento. Dentro das empresas as pessoas que trabalham diretamente com os consumidores podem ser divididas entre provedores de serviço e pessoal de contato. Os provedores de serviço são as pessoas que realizam o serviço final, como médicos e dentistas. Já o pessoal de 
contato, são as pessoas com quem os consumidores têm contato breve, como recepcionistas e atendentes. Tanto os provedores de serviço quanto o pessoal de contato devem estar altamente motivados e treinados para realizar os atendimentos ao público. Las Casas (2008) salienta a importância das empresas e dos profissionais de marketing estarem atentos às pessoas que fazem parte do processo. O nível cultural, a educação e o modo de se relacionar com os clientes podem ser decisivos para o consumo dos produtos oferecidos pela empresa. Por isso, a empresa deve preocupar-se com o treinamento constante de seus colaboradores, afim de aperfeiçoar e melhorar o desenvolvimento das equipes.

f) Processos: Para Cobra e Urdan (2017) os processos são todas as atividades e ações que levam o cliente a aproveitar os benefícios dos produtos ou serviços que adquire na empresa, desde a negociação até o pós-venda. Las Casas (2008) destaca que cabe ao profissional de marketing planejar todos os processos que o consumidor irá passar, desde sua entrada até a sua saída da empresa. Kotler e Keller (2013) afirmam que quando a organização consegue implantar um conjunto de processos de forma precisa também no ambiente online, os resultados são positivos nos relacionamentos a longo prazo.

g) Programas: Para Kotler e Keller (2013) os programas se referem a todas as atividades que se dirigem ao consumidor, tanto on-line, quanto off-line. Um dos principais programas é marketing sensorial. De acordo com Camargo (2013) o marketing sensorial é um conjunto de elementos desenvolvidos por meio dos cinco sentidos: visão, audição, tato, olfato e paladar, que se aplica principalmente com a finalidade de fazer o cliente ficar mais tempo dentro do ponto de venda e, possivelmente, comprar mais.

h) Performace: De acordo com Kotler e Keller (2013) a performance abrange os resultados da empresa, sendo eles financeiros ou não financeiros, além de fatores que superam as empresas, como a ética e a responsabilidade social. Em relação à performance de uma empresa, a marca é considerada um dos fatores mais importantes e fundamentais. 


\subsection{Relações de gênero: e empoderamento digital}

Conforme Silvino e Henrique (2017), os estudos sobre gênero estão diretamente ligados às construções sociais de homens e mulheres, diferente do que se entendem por sexo somente. Segundo Haraway (1954 apud CORREA E MENDES, 2015), sexo é um conceito relacionado às características físicas dos seres humanos, e gênero é a definição cultural e social criada a partir das características atribuídas ao sexo, ou seja, sexo é a forma natural e biológica humana, e gênero é entendido como uma construção social. De acordo com Santos (2008), as noções de gênero como uma divisão social reforçam a ideia de que as diferenças entre os gêneros possuem origem estrutural e social.

Scott (1989) afirma que o gênero engloba quatro elementos: as identidades, as instituições, os símbolos e os conceitos normativos. Santos (2008) afirma que a indefinição de categorias de gêneros tem sido uma tendência em nível mundial, e está entre as dez maiores tendências do marketing para os próximos anos (EUROMONITOR, 2016 apud LEITE, 2016). Segundo Ayer (2017), a tendência da moda sem gênero já aponta para um mercado em expansão em que se busca uma valorização do ser humano com um indivíduo único.

De acordo com Cruz (2017), o marketing realiza a importante função de naturalização das relações de poder envolvendo as questões de gênero por meio das representações dos papeis sociais dos homens e mulheres. Rocha (2006) explica que as questões demonstradas pela publicidade são complexas e diversas, e as identidades masculinas e femininas se traduzem na mídia como os padrões e códigos em que a sociedade mescla práticas e estilos.

Cruz (2017) complementa que, ao observar a relação entre comunicação publicitária e cultura, é possível ver as contradições da sociedade e as manifestações que fortalecem as distinções dos gêneros. Segundo Conde e Hurtado (2006), os estereótipos são as representações da realidade igualmente resistentes à mudança, e na publicidade seu uso acentua os prejuízos de gênero pela resistência de adaptação, reproduzindo a discriminação sexual. Araújo (2014) complementa essa ideia, afirmando que se a publicidade agisse de maneira igual para homens e mulheres, mostrando para o público feminino mais conteúdo positivo do que negativo, as mulheres poderiam adotar posturas 
diferentes em relação ao seu corpo e sua autoestima. Nesse contexto, Araújo (2014) também realiza o questionamento de que se os estereótipos estão tão presentes na publicidade e são tão espontâneos, é possível evitar o uso dos mesmos?

Conforme Cruz (2017) é possível observar que já estão ocorrendo mudanças. Algumas marcas tem utilizado uma construção de situações inesperada em seus anúncios para desconstruir as expectativas dos consumidores em cenas que envolvem as relações de gênero. As situações contemplam a inversão dos comportamentos considerados tradicionais, por exemplo, homens responsáveis pela limpeza e cuidado com a família e mulheres executivas e consumidoras de cervejas.

Para Kotler, Kartajaya e Setiawan (2017) as relações de poder estão mudando, tornando-se cada vez mais sociais e inclusivas. Os consumidores estão mais empoderados e as relações de poder verticais estão sendo transformadas pela força das novas relações de poder horizontais e, como consequência dessa mudança, o poder não se concentra mais nos indivíduos e sim nos grupos sociais. Esses grupos sociais se tornaram uma importante fonte de influência, ultrapassando as preferências pessoais e as comunicações de marketing. Ou seja, os consumidores estão valorizando cada vez mais as opiniões de outros consumidores e utilizando seus círculos sociais para se defender de campanhas publicitárias falsas. Dessa forma, com o aumento constante da conectividade, as decisões pessoais serão cada vez decisões sociais, tanto on-line como off-line.

Com isso, Sibilia (2003) afirma que a sociedade atual sente a necessidade de expor-se, fenômeno denominado "imperativo de visibilidade". Esse fenômeno é uma consequência da globalização e do aumento da conectividade, uma vez que para existir no ambiente virtual é necessário ser visto. Nesse contexto, Recuero (2009) afirma que uma rede social é um conjunto de dois elementos, os atores e suas conexões. Os atores são partes do sistema e formam as estruturas sociais por meio da interação e dos laços sociais. As interações são as ações que acontecem entre os indivíduos e geram laços sociais, que são as conexões existentes entre os atores, composto pelas relações sociais (RECUERO, 2009). 


\section{Metodologia}

Para o presente estudo optou-se por utilizar a abordagem qualitativa, com o método descritivo (PRODANOV E FREITAS, 2013). A técnica de pesquisa utilizada é a netnografia, conforme Kozinets (2014) a netnografia é um tipo de pesquisa que se baseia no trabalho de campo on-line utilizando as comunicações via computadores como fonte de dados para chegar à representação etnográfica de um fenômeno cultural. Os principais autores utilizados como marco teórico foram Kotler e Armstrong (2015), Las Casas (2008), Camarotto (2009), Kotler, Kartajana e Setiawan (2017), Camargo (2013), Silvino e Henrique (2017), Santos (2008), Recuero (2009), Cruz (2017), Rocha (2006), Araújo (2014).

Após a realização da pesquisa bibliográfica utilizou-se a técnica de análise de redes sociais (KOZINETS, 2014) com a seleção do Facebook da marca Youcom que conta com 1.078.322 curtidas. Quanto a amostra utilizada nessa pesquisa foi a amostra não-probabilística por conveniência. Utilizou-se a observação sistemática e não-participante que ocorreu entre os dias 12 de julho de 2018 até 18 de julho de 2018, sendo que foram analisados os posts de 01 de janeiro de 2018 até 30 de junho de 2018. Na realização dessa pesquisa utilizouse a análise de conteúdo conforme Prodanov e Freitas (2013), dividindo-se a análise em três etapas. Primeiramente, na etapa de pré-análise ocorreu a coleta de dados, na segunda etapa da análise, a exploração do material e definição das categorias que são os 8ps e, por fim, na terceira etapa de tratamento dos resultados, relacionou-se o referencial teórico da pesquisa juntamente com os dados coletados.

\section{Resultados e Discussão}

No período analisado, a marca Youcom realizou 279 publicações na sua página do Facebook, e houve 127.253 interações de atores. Desse total, 122.266 foram LIKES, 4.341 AMEI, 250 HAHA, 298 UAU, 53 TRISTE e 45 GRR. Recuero (2009) afirma que os atores formam estruturas sociais através de interações. Sendo assim, observa-se que as publicações da marca Youcom obtêm um número 
significativo de interações dos atores. Evidencia-se que as interações realizadas nas postagens da marca Youcom, no período analisado, são positivas, pois o número de interações tristes e grr não é expressivo diante do total de 127.253 interações. A seguir são detalhadas as táticas de marketing observadas na pesquisa netnográfica.

\subsection{Produto}

Sobre os atributos dos produtos, conforme Kotler e Armstrong (2015) o estilo e design podem atrair a atenção dos clientes e enfatizar as utilidades dos produtos. De acordo com a coleta de dados, verificou-se que os consumidores percebem e identificam-se o estilo e design da Youcom e, em alguns posts, solicitam dicas de moda e de uso dos produtos:

Cliente A: T-shirts lindas! E dá para usar com alfaiataria?

Cliente B: Dá pra usar vinil durante o dia?

Cliente $\boldsymbol{C}$ : Como misturar a saia xadrez tendência com outras peças?

Cliente B: como dar um up no jeans?

Cliente D: Quero muito esse teu vestido (ㅇ) ()을

Cliente E: quero uma vinil -

Cliente F: Kkkkk a costura ta no meio da perna e modelo 2018

YOUCOM: Vc quer coleção bapho @?

Nos comentários da postagem, evidencia-se que a marca Youcom, ao falar sobre sua coleção, não faz distinção sobre os gêneros de seus consumidores. A marca comenta com @, não direcionando para um consumidor específico. Conforme Euromonitor (2016 apud LEITE, 2016), a indefinição das categorias de gênero é uma tendência do marketing mundial. A seguir, mais um exemplo de postagem da marca, na qual os consumidores demonstram identificação com as características do produto e comentando com amigos e amigas:

Cliente A Cliente B olha migs! Sua cara esse look.

Cliente $B$ Tbm achei $(0 \Theta \Theta \Theta \Theta$

Cliente $C$ Cliente $D$ olha essa calça

Cliente E Qro uma assim curta e larga

Cliente F Cliente $\mathbf{G}$ achei essa calça tua cara

Cliente H Cliente I, mira, uma delas é a mom jeans@)

Cliente $\boldsymbol{J}$ já amei 
Revista Multidisciplinar do Nordeste Mineiro, v.1,

Para Kotler e Armstrong (2015) as características dos produtos podem gerar valor para os clientes. Las Casas (2008) complementa que o produto deve ser desenvolvido para atender os desejos e as necessidades dos clientes. Sendo assim, conforme comentários dos consumidores, observa-se que os produtos da marca Youcom, sem fazer a distinção dos gêneros, possuem características que os aproximam dos consumidores. Que remete também as citações de Cruz (2017) que relacionam que a publicidade e a cultura devem observar as manifestações de distinções de gênero.

Conforme descrito, para Rocha (2006) as questões apresentadas pela publicidade são complexas e as identidades femininas e masculinas se traduzem na mídia por meio de códigos e padrões. Esta complexidade é observada na figura 1 , pois mesmo sendo uma publicação com um modelo masculino, um consumidor realizou um comentário machista sobre o produto.

Figura 1: Post Youcom - Produto

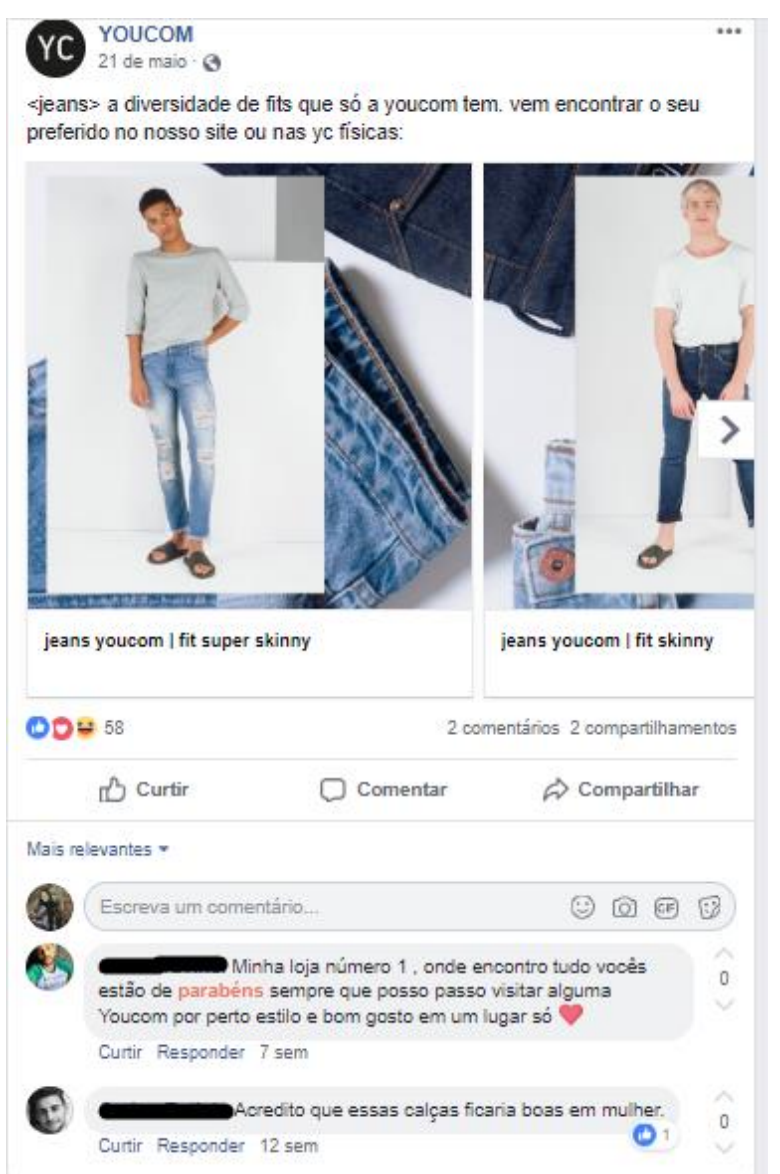

Fonte: facebook.com/lojayoucom - 2018 
Revista Multidisciplinar do Nordeste Mineiro, v.1,

2021/01

ISSN 2178-6925

A marca optou por não se posicionar diante deste comentário, assim como também não se posicionou em relação ao elogio feito por outro consumidor na mesma postagem.

\subsection{Preço}

Conforme descrito, Las Casas (2008) aborda que os consumidores analisam a relação ao custo $X$ benefício que o produto pode trazer. Conforme a figura 2 evidencia-se que a marca opta por divulgar seus preços nas postagens das redes sociais:

Figura 2: Post Youcom - Preço

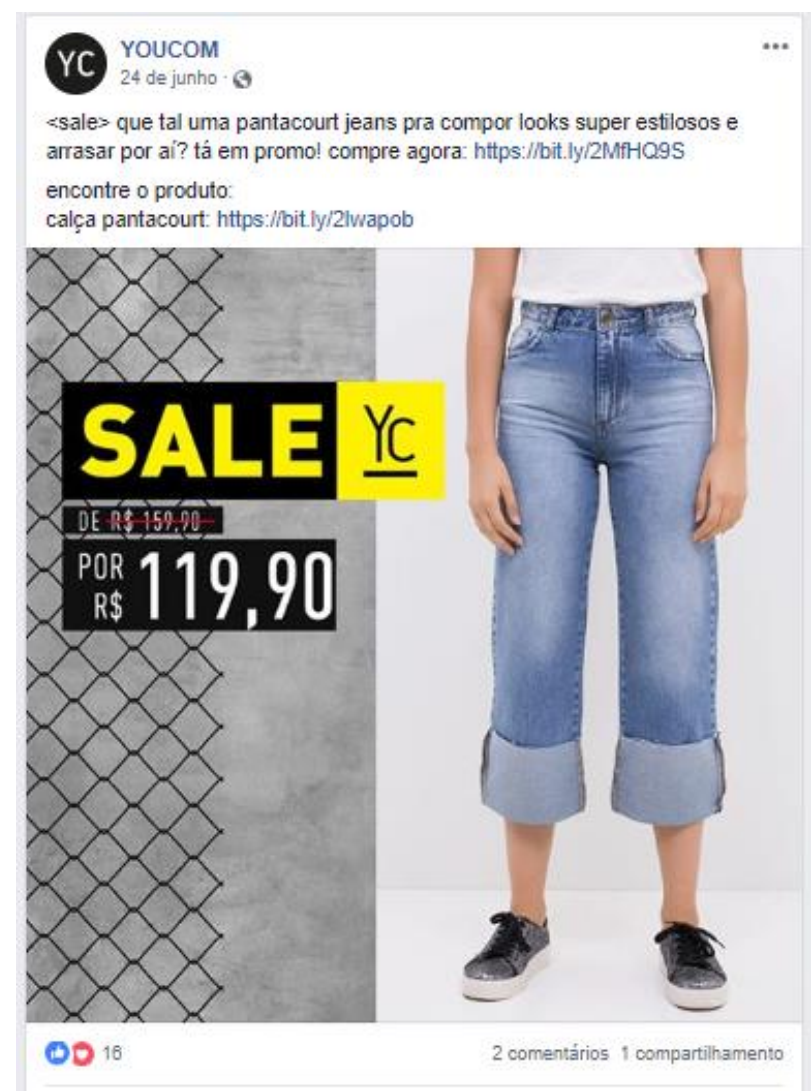

Fonte: facebook.com/lojayoucom - 2018

Também se evidencia nesse caso, que a divulgação dos preços está em produtos sem estereótipos de gênero, não direcionando para homens ou mulheres. 
Revista Multidisciplinar do Nordeste Mineiro, v.1,

2021/01

ISSN 2178-6925

\subsection{Praça}

Segundo Kotler e Armstrong (2015), a praça se refere a todas as ações da empresa com o objetivo de disponibilizar os produtos para os clientes. $\mathrm{Na}$ realização da pesquisa também se verificou que os consumidores sugerem para a Youcom a abertura de novas lojas, conforme o comentário a seguir:

Cliente A Borá abrir loja em cruz alta - YOUCOM ;)

Cliente B Eu sou apaixonado pela YOUCOM, ao entrar na loja é impossível vc não sair com pelo menos uma peça, sem contar que as roupas não tem sexo na loja, é bem desconstruída, e isso é o que deixa a marca muito mais atrativa.

Youcom aii Cliente B a gente fica $\mathrm{mt}$ feliz em saber! feedbacks são sempre importantes ;)

Além da sugestão de uma nova loja da marca, evidenciou-se que os consumidores se identificam com a proposta da loja e o conceito da marca. Conforme Kotler, Kartajaya e Setiawan (2017), os consumidores estão cada vez mais empoderados e as relações de poder estão mais horizontais. Dessa forma, os consumidores utilizam seu poder e unem-se formando grupos sociais, buscando marcas com as quais se identificam e nas quais espelham suas opiniões e atitudes.

Churchill e Peter (2012) descrevem que o modo escolhido pelo profissional de marketing para disponibilizar o produto para os consumidores influencia na percepção dos mesmos sobre o produto e na percepção sobre a compra. Conforme evidenciado na análise de redes sociais, os consumidores dos produtos da marca Youcom reconhecem que o modo como as lojas são organizadas oferece mais atratividade para a marca, influenciando na hora de realizar uma compra.

Para Kotler, Kartajaya e Setiawan (2017), ao tomar uma decisão de compra, os consumidores sentem-se impulsionados pelo desejo de conformidade social, compartilhando suas opiniões e influenciando suas decisões pessoais em decisões sociais. Sendo assim, no comentário do consumidor B, descrito acima, observa-se a expressão de sua opinião pessoal sobre a marca refletindo para os outros consumidores.

De acordo com Santos (2008), as relações de gênero demonstram as desigualdades, além das categorias homens e mulheres, presentes nas estruturas da sociedade. No comentário do Cliente $B$, também se evidencia a ideia de 
Revista Multidisciplinar do Nordeste Mineiro, v.1,

desconstrução por meio das roupas sem sexo oferecidas nas lojas da marca Youcom e como essa desconstrução influencia na identificação com a marca e seus produtos.

\subsection{Promoção}

Segundo Kotler e Armstrong (2015) a promoção tem o objetivo de criar uma comunicação e relacionamento com os clientes, demonstrando seus valores. Parente e Barki (2014) complementam tal afirmação, apontando que se trata de uma ferramenta que oferece um valor para o consumidor.

A promoção da marca Youcom evidencia que a empresa não utiliza os estereótipos em sua publicidade e busca oferecer produtos sem a distinção de gênero e que podem ser úteis para ambos os gêneros, conforme demonstrado na figura 3:

Figura 3: Post Youcom - Promoção Dia dos Namorados

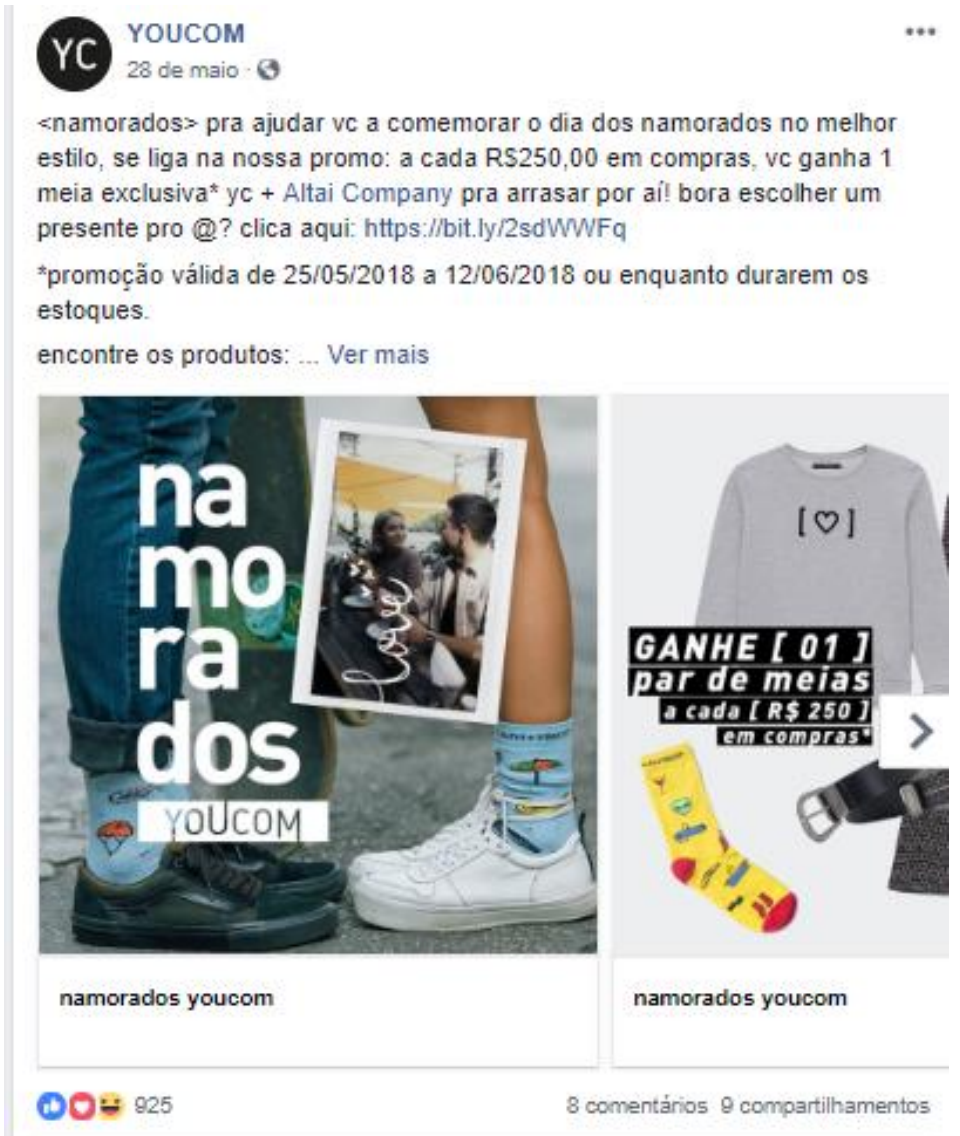

Fonte: facebook.com/lojayoucom - 2018 
A figura 3 demonstra a promoção realizada pela marca Youcom para o dia dos namorados. A promoção consiste no brinde de um par de meias após realizar uma compra no valor de $\mathrm{R} \$ 250,00$. Ao escolher por presentear seus consumidores com um par de meias, a marca Youcom não faz a distinção do brinde por gênero, sendo um presente igual para quem realizar a compra.

Sendo assim, evidencia-se que a marca Youcom buscou presentar seus consumidores por meio de uma promoção que oferece um brinde igual para todos, indiferente do gênero. Na figura 3 também se evidencia que a marca não direciona sua promoção para o gênero dos namorados, pois promove novamente apenas o @, representando qualquer gênero para os consumidores. Por meio do uso do @ sem direcionar a nenhum gênero específico, a marca Youcom oportuniza que seus consumires adotem a promoção de acordo com seu estilo e comportamento.

\subsection{Pessoas}

Cobra e Urdan (2017) afirmam que as pessoas são fundamentais na transmissão da imagem da empresa para os consumidores e, por isso, pessoas motivadas podem criar uma boa experiência para os consumidores. $\mathrm{Na}$ análise de redes sociais isso foi evidenciado conforme o comentário a seguir, em que a consumidora exemplifica como o vendedor foi atencioso e resolveu o problema com o produto:

Cliente A Olá. ALEGRIA Fui até a loja, conversei com o vendedor e imediatamente ele providenciou a troca por outro produto e pediu-me desculpas pelo ocorrido. Agradeço a YouCom pelo trabalho e treinamento de seus vendedores, que me atenderam com muita simpatia. Troquei por uma calça camuflada e aproveitei para levar uma camiseta preta de veludo linda. Obrigada a equipe da empresa

YOUCOM nós que ficamos felizes! pedimos desculpas mais uma vez pelo ocorrido e qualquer coisa estamos aqui $\theta-$

No comentário da consumidora, fica claro seu agradecimento para a marca e evidencia-se seu agradecimento pelo treinamento de seus vendedores. De acordo com Las Casas (2008), é fundamental que a empresa possua um plano de treinamento para sua equipe, com treinamentos constantes a fim de melhorar o desenvolvimento. 


\subsection{Processos}

Para Las Casas (2008), os processos são uma série de interações entre a empresa e o consumidor que ocorrem desde o momento em que o consumidor chega na empresa até a efetivação da compra. Sendo assim, o profissional de marketing deve planejar todos os processos que os consumidores irão utilizar. $\mathrm{Na}$ coleta de dados realizada, foi encontrada esse exemplo de opinião de um consumidor sobre os processos da marca:

Cliente A: Loja top. Peças lindas e de muita qualidade, porém não aceitam pagamento via boleto bancário e quem não tem cartão fica sem comprar. Simples assim.

Conforme evidenciado no comentário, o consumidor prestigia a marca e suas lojas e elogia os produtos e a qualidade. Entretanto, o consumidor ressalta sua insatisfação com as condições de pagamento para a realização de compras via internet. Segundo Cobra e Urdan (2017), os processos devem beneficiar os clientes, contribuindo para um melhor aproveitamento dos produtos e serviços.

Em outro comentário obtido na coleta de dados, verificou-se que o consumidor teve boas experiências com a marca, pois elogia a loja e os produtos.

Cliente A: Uma das melhores lojas $\Theta \Theta \Theta \Theta e$ as roupas são maravilhosas.

\subsection{Programas}

De acordo com Kotler e Keller (2013), os programas são todas as atividades on-line e off-line que se direcionam para os consumidores. E, para Parente e Barki (2014) o varejo eletrônico é uma ferramenta muito importante atualmente. No comentário a seguir evidencia-se que o consumidor aprecia o site oficial da marca Youcom, sendo que o Cliente B relata identificar-se fisicamente com o modelo utilizado na campanha da marca:

\section{Cliente A Amei!}

Cliente B Amei o site, e vim aqui dizer que esse cara é meu irmão gêmeo. $\|^{\eta}$

Camargo (2013) destaca o marketing sensorial como uma ferramenta para fixar a marca na mente do consumidor. Essa ferramenta consiste em um conjunto de elementos manifestados nos cincos sentidos dos consumidores: visão, audição 
olfato, tato e paladar. Um evento realizado pela Youcom na praia de Atlântida - Rio Grande do Sul, demonstra a execução do marketing sensorial para seus consumidores.

Neste evento a marca proporcionou um programa diferenciando para seus consumidores, e teve a oportunidade de atrair novos clientes. Outro uso deste "P" realizado pela marca Youcom foi a criação de playlists próprias e divulgação das mesmas em sua página oficial do Facebook. A figura 4 demonstra a divulgação da playlist de dia dos namorados:

Figura 4: Post Youcom - Playlist dia dos namorados

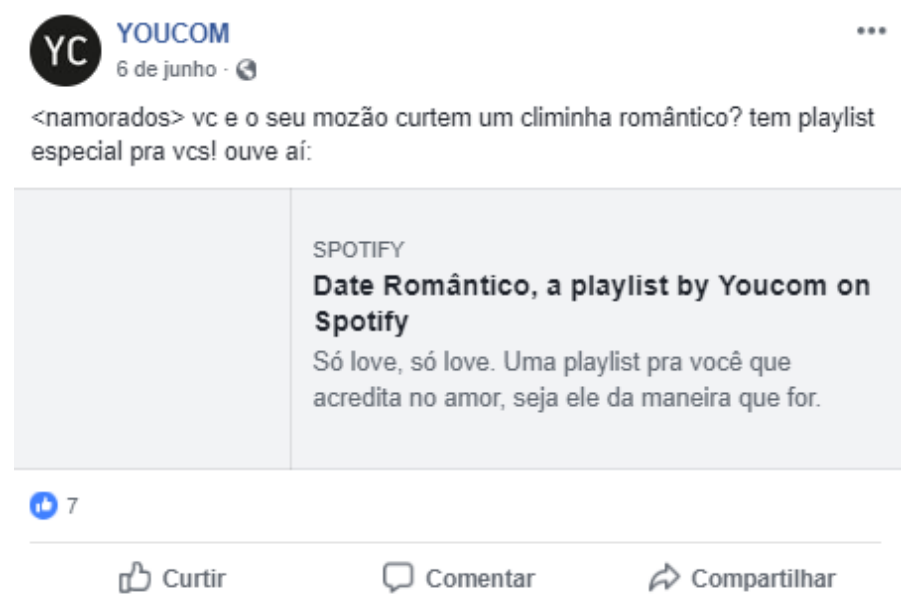

Fonte: facebook.com/lojayoucom - 2018

Na figura 4, evidencia-se que a marca Youcom explorou de forma intensa o sentido da audição, como um elemento do marketing sensorial fazendo-se presente na memória dos consumidores. A marca também faz a descrição da playlist como: "pra você que acredita no amor, seja ele da maneira que for". Sendo assim, a Youcom não direciona sua publicação e a playlist para nenhum gênero específico, oferendo a liberdade para os consumidores usufruírem das músicas oferecidas pela marca como melhor entenderem e como melhor encaixar-se em suas vidas.

\subsection{Performace}

De acordo com Kotler e Keller (2013), a performance envolve todos os resultados da empresa, sendo eles os resultados financeiros e os não financeiros. Um dos fatores fundamentais para a performance das empresas é a marca. Para 
Revista Multidisciplinar do Nordeste Mineiro, v.1,

2021/01

ISSN 2178-6925

Kotler e Armstrong (2015), os consumidores entendem que a marca é uma parte importante do produto ou serviço. A figura 5 ilustra o logotipo da marca Youcom:

Figura 5: Logotipo Youcom

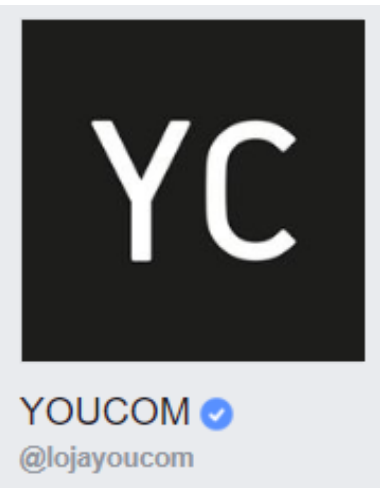

Fonte: facebook.com/lojayoucom - 2018

Conforme a figura 5 evidencia-se que a marca Youcom não direciona sua identidade. Ela possui um logo neutro, em preto e branco, e os símbolos são as letras iniciais da marca. Para Cruz (2014), a publicidade tem buscado romper a expectativa dos consumidores nas relações de gênero. A figura 6 demonstra o slogan utilizado pela marca:

Figura 6: Slongan Youcom

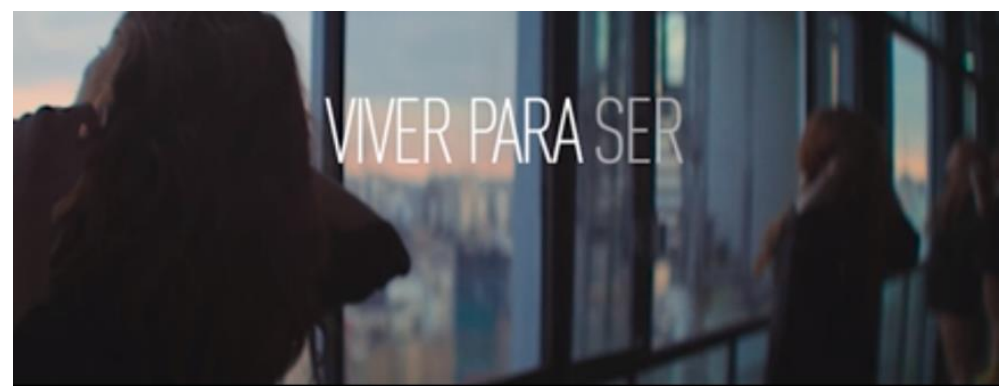

Fonte: facebook.com/lojayoucom - 2018

Ao utilizar o slogan "Viver para ser", evidencia-se que a Youcom se posiciona de forma aberta para seus consumidores, indicando que os mesmos podem viver e ser da maneira que lhes convém. Ao adotar esse posicionamento, a marca coloca em prática o atributo da emocionalidade. Segundo Kotler, Kartajaya e Setiawan (2017), a emocionalidade é um atributo pelo qual as marcas podem se relacionar com seus consumidores e influenciá-los. 
Kotler e Keller (2013) salientam que as marcas são ativos importantes das organizações, sendo capazes de influenciar seus consumidores. Os comentários obtidos na coleta de dados demonstram que os consumidores da Youcom reconhecem e identificam-se com a marca:

Cliente A: Eu amo essa loja $\Theta \Theta$

Cliente B: Cliente $\mathrm{C}$ quando a loja faz eu ama-la mais

Cliente C: Vou ter que te levar sempre cmgo agora haha

Cliente D: Amo minha loja

Cliente E: Amooo. Pisa menosssss

Cliente F: Me dá um emprego youcom amo a loja

Cliente G: Amoooo $\Theta \Theta \odot$

Ao concretizar o posicionamento de não direcionar seus programas para um gênero específico, a marca Youcom contribui para as ações que buscam a igualdade de gênero.

\section{Conclusão}

Novos formatos de consumo e as alterações nas mudanças de poder vêm exigindo cada vez mais das empresas. As novas tecnologias estão mais presentes no dia-a-dia, trazendo novas possibilidades para os consumidores no que tange ao conhecimento de novos produtos e serviços, como também no que diz respeito ao acompanhamento do que de fato as empresas estão realizando.

Diante dos novos cenários, cabe às empresas compreenderem as mudanças e buscar o conhecimento para atualizarem-se de forma constante. Sendo assim, torna-se muito importante a empresa reconhecer e estruturar o seu marketing, afinal, essa é a área da empresa que administra o planejamento e as ações entre a empresa e seus consumidores. Também se torna fundamental que a empresa e todas as suas áreas prezem pelo respeito à diversidade em suas práticas.

Essa pesquisa abordou a análise do Facebook da marca Youcom com o intuito de analisar a influência das relações de gênero nas táticas de marketing da empresa. Nos resultados obtidos evidenciou-se que a marca possui um forte 
posicionamento sobre as relações de gênero. A Youcom não faz a distinção dos gêneros em suas lojas físicas e e-commerce, em seus produtos e em suas táticas de marketing. A marca direciona seu foco para o público jovem de um modo geral e não distingue os gêneros, possibilitando a liberdade de seus consumidores. Também foi verificado que os consumidores da marca Youcom compreendem e identificam-se com posicionamento da mesma.

Por fim, os aprendizados decorrentes desse trabalho possibilitam a compreensão de como o modo em que as empresas se posicionam podem influenciar seus consumidores. $\mathrm{E}$, ao mesmo tempo, o modo como os consumidores, cada vez mais empoderados, esperam e identificam-se com o posicionamento das empresas.

\section{Referências}

ARAÚJO, S. Publicidade Sem Estereótipos de Gênero - Dá Pra Fazer? Revista Comunicando, 2014

\section{AYER, F. Moda sem gênero ganha cada vez mais simpatizantes e aponta} mercado em crescimento. 2017. Disponível em: < https://www.em.com.br/app/noticia/economia/2017/07/16/internas_economia,8842 17/moda-agora-e-sem-genero.shtml> Acesso em: 30 Ago. 2020.

CAMARGO, P. C. J. de. Neuromarketing: a nova pesquisa de comportamento do consumidor. São Paulo: Atlas, 2013.

CAMAROTTO, M. R. Estratégia de Marketing. Curitiba, Paraná: IESDE, 2009. CHURCHILL, G. A; PETER, P. Marketing: criando valor para os clientes. São Paulo: Saraiva, 2012.

COBRA, M.; URDAN, A. T. Marketing básico. São Paulo: Atlas, 2017.

CONDE, M. R; HURTADO, M. La mujer y el hombre em la publicidade televisiva: imágenes y estereótipos. Zer Revista de estudos de Comunicación, Universidad del País Vasco, 2006.

CORREA, L. G.; MENDES, A. M. Inversão, desnaturalização e reforço de práticas de gênero em peças publicitárias. Revista Intexto. Porto Alegre: UFRGS, 2015.

CRUZ, M. F. O. Representações do feminino na publicidade: estereótipos, rupturas e deslizes. Revista Latinoamericana de Comunicación, Ecuador, 2017.

KOTLER, P.; ARMSTRONG, G. Princípios de Marketing. 15 ed. São Paulo: Pearson Prentice Hall, 2015. 
KOTLER, P.; KARTAJAYA, H.; SETIAWAN, I. Marketing 4.0: do tradicional ao digital. Rio de Janeiro: Sextante, 2017.

KOTLER, P.; KELLER, K. L. Marketing essencial: conceitos, estratégias e casos. 5 ed. São Paulo: Pearson Prentice Hall, 2013.

KOZINETS, R. V. Netnografia: realizando pesquisa etnográfica online. São Paulo: Penso, 2014

LAS CASAS, A. L. Administração de marketing: conceitos, planejamento e aplicações à realidade Brasileira. São Paulo: Atlas, 2008.

LEITE, Renata. 10 tendências globais de consumo, segundo a Euromonitor Internacional. Mundo do marketing. 2016. Disponível em:

https://www.mundodomarketing.com.br/reportagens/mercado/35463/10-

tendencias-globais-de-consumo-segundo-a-euromonitor-internacional.html.

Acesso em: 30 Ago. 2020.

PARENTE, J.; BARKI, E. Varejo no Brasil: gestão e estratégia. São Paulo: Atlas, 2014.

PRODANOV, C. C.; FREITAS, E. C. Manual de Metodologia do trabalho científico: métodos e técnicas da pesquisa e do trabalho acadêmico. 2 ed. Novo Hamburgo: Feevale, 2013.

RECUERO, R. Redes sociais na internet. Porto Alegre: Sulina, 2009.

RENNER, SA. Nossos negócios - Youcom. 2020. Disponível em:

http://www.lojasrennersa.com.br/pt_br/nossos-negocios/youcom. Acesso em: 18 Ago. 2020.

ROCHA, E. P. G. Representações do consumo: estudos sobre a narrativa publicitária. Rio de Janeiro: Ed. PUC-Rio \& Mauad, 2006.

SANTOS, J. A. F. Classe social e desigualdade de gênero no Brasil. Revista Dados de Ciências Sociais. Rio de Janeiro, 2008.

SCOTT, J. Gender: a useful category of historical analyses. Gender and the politics of history. New York, Columbia University Press, 1989.

SIBILIA, P. Os diários íntimos na internet e a crise da interioridade psicológica do sujeito. Grupo de Tecnologias Informacionais da Comunicação e Sociedade, XII Congresso da Associação Nacional de Programas de Pós-Graduação em Comunicação COMPOS, Niterói/ RJ, 2003.

SILVINO, D. M.; HENRIQUE, T. R. P. G. A importância da discussão de gênero nas escolas: uma abordagem necessária. Universidade Federal do Maranhão. 2017. Disponível em:

http://www.joinpp.ufma.br/jornadas/joinpp2017/pdfs/eixo6/aimportanciadadiscussa odegeneronasescolasumaabordagemnecessaria.pdf. Acesso em: 05 Ago. 2020.

YOUCOM. Facebook. Disponível em: www.facebook.com/lojayoucom. 2018. Acesso em: 05 Ago. 2018.

YOUCOM. Site. Disponível em: www.youcom.com.br. 2018. Acesso em: 05 Ago. 2018. 